\title{
Impact of Tobacco Expenditure on Household Spending Patterns in Kenya
}

\section{ESJ Social Sciences}

\section{Peter Magati}

School of Economics, University of Nairobi, Kenya

\section{Leopold Mureithi}

School of Economics, University of Nairobi, Kenya

\section{Wilfred Nyangena}

School of Economics, University of Nairobi, Kenya

Submitted: 06 October 2020

Accepted: 23 November 2020

Published: 30 November 2020

Corresponding author:

Peter Magati

DOI: 10.19044/esj.2020.v16n31p260

cc) Copyright 2020 Peter Magati et al. Distributed under Creative Commons BY-NC-ND 4.0 OPEN ACCESS

\begin{abstract}
Despite measures to control tobacco use in Kenya, there is still an increasing importance in the use of tobacco. This is seen by the growth in per capita consumption over time. Tobacco, being an addictive product, creates a situation where consumers allocate part of their resources towards its consumption and therefore positions the use of tobacco as an important expenditure decision in households in Kenya. Due to budget constraints faced by households in Kenya, tobacco consumption may crowd out consumption of essential goods and services. This paper therefore focuses on the impact of tobacco expenditure on household spending patterns in Kenya. Using the 2005/2006 Kenya Integrated Household and Budget survey, a Quadratic Almost Ideal Demand System was used to estimate a system of Engel curves to check whether the differences in expenditure between the two types of households is as a result of tobacco use or not. Results suggest that tobacco crowds out the consumption of food, health care, schooling, clothing, entertainment, house care, and personal care. Geographical location and socio-economic standing of households have a significant influence on the magnitude and pattern of crowding out. The policy implication of this finding is that tobacco control should be an integral part of governments' poverty alleviation strategy.
\end{abstract}

Subject: Business

Keywords: Tobacco use, crowding out, essential household expenditure items 


\section{Introduction}

It is estimated that at least 6 million deaths and almost $4 \%$ of global diseases are a direct result of tobacco use (Forouzanfar et al., 2015). In Kenya, tobacco related diseases contribute directly to deaths of at least 6,000 annually. Despite this, over 2,737,000 adults and more than 220,000 children use tobacco each day (Eriksen et al., 2015). Tobacco consumption has adverse effects on households. First, it is estimated that at least 6 million deaths and almost $4 \%$ of diseases globally are directly attributed to tobacco use (Forouzanfar et al., 2015). It is estimate that by the year 2030, the highest burden of disability and premature mortality will be as a result of tobacco higher than any other health risk factor. If not prioritized in control, tobacco use will produce the highest mortality. Research suggests that compared to other health risk factors, the highest burden will be in low and medium-income countries (Mathers \& Loncar, 2006). Secondly, and more importantly to this study, tobacco use contributes to adverse effect on household nutrition, poverty, and income. There are studies that suggest that households that consume tobacco have higher child stunting and generate lower income from assets (Wood et al., 2005). Tobacco use is also associated with higher poverty rates and lower spending on health care, clothing, education, and food (Efroymson et al., 2001; Pu et al., 2008; Koch \& Tshiswaka-Kashalala, 2008; John, 2008).

Kenya realized the risk emanating from tobacco use and ratified the World Health Organization Framework Convention on Tobacco Control (WHO FCTC) in 2004. To operationalize the WHO FCTC, the Kenya Tobacco Control Act (KTCA) was accented by Parliament in 2007. The Act provides the legal framework that regulates the production of tobacco leaf, manufacture of cigarettes, and the sale and advertisement of tobacco products (Republic of Kenya, 2007a).

Tobacco consumption in Kenya has been increasing progressively since 2006. Data suggests that per capita consumption of cigarette in Kenya has been rising (see Figure 1) and is expected to continue increasing based on the trend. Tobacco, being an addictive product, creates a situation where consumers allocate part of their resources towards its consumption. This therefore positions the use of tobacco as an important expenditure decisions for households in Kenya. Due to budget constraints faced by households in Kenya, tobacco consumption may crowd out consumption of essential goods and services. Despite this, however, there is limited information on the impact of tobacco use on household expenditure patterns in Kenya - a gap that this paper seeks to address. 


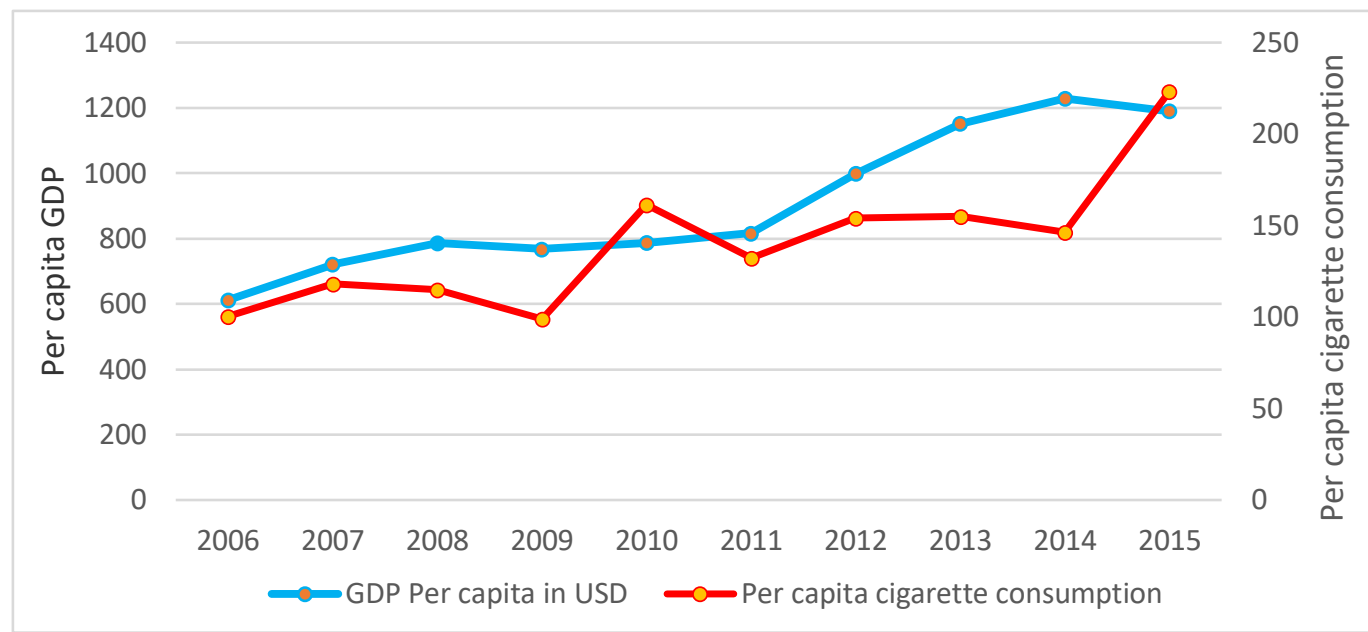

Figure 1. Per Capita Tobacco Consumption and Per Capita GDP in Kenya Source: Republic of Kenya, 2007-2016

\section{Materials and Methods}

The paper follows the theoretical framework as laid down in John (2008). Here, we assume that a household seeks to maximize utility in the manner built by Samuelson (1956) and Becker (1974). Due to the challenge of incorporating intra-household interaction in the data, utility maximization in the households generally results in a set of $z$ household Marshallian demand functions of the form:

$$
X_{n}=\left(p_{n} \ldots p_{z} ; Y, c\right) \text {. }
$$

Where $x_{n}$ is quantity purchased of the $n^{\text {th }}$ commodity, $p_{n}$ is the price of the $n^{\text {th }}$ commodity, $Y$ is the total household income, and $a$ is a vector of household characteristics.

The assumption of the model shows that a household that smokes tobacco is one in which any member smokes. The household pre-determines the quantity of tobacco that will be purchased before deciding on other commodities that will be purchased in the household. The rationale behind this approach is the addictive nature of nicotine, which means that the maximization of the household's utility is subject to an expenditure amount that remains after the household has purchased tobacco. This situation, therefore, results to the optimization problem of utility maximization with a set of conditional demand functions of the form:

$$
x_{n}=b_{n}\left(p_{n} \ldots . p_{z} ; M ; c, d\right) \text {. }
$$

Where $d$ is an indicator variable for tobacco expenditure in a household and $M$ is the income that remains after the household has already spent on tobacco. Demand by the household on commodity $n$ is subject to its smoking 
status. This suggests the possibility of the comparison of conditional demand functions of smoking households and Marshallian demand functions for nonsmoking households. Hence, this is with any difference in the quantities consumed being attributed to tobacco.

Assuming there are $z$ number of goods in the market and tobacco is the $z^{\text {th }}$ goods, the household will have no control over $z-1$ goods whose market prices are given as $P_{1}, \ldots . ., P_{z-1}$. It follows, therefore, that the total expenditure of the household on these goods will be given by $M\left(M=M-P_{t} t\right)$ where $P_{t} t$ is the tobacco expenditure. Therefore, the utility maximization problem assumes the following form:

$\operatorname{Max} \mathrm{U}=U\left(x_{1}, \ldots, x_{z} ; c\right)$ s.t $\sum_{i=1}^{z-1} p_{i} x_{i}=M$

with the additional constraint $x_{z}=\bar{x}_{z}$ where $\bar{x}_{z}$ is the household's demand for tobacco.

Following the presentation of the theoretical model, this paper used the econometric model laid out in Chelwa and Van Welbeek (2014). The paper first compared the mean expenditures of various commodities in the household between the tobacco consuming and non-consuming households. Specifically, comparisons were made in the following expenditure categories: food, healthcare, alcohol, water, housing, lighting and electricity, alternative energy sources, transport and communication, entertainment and personal care, school, clothing and household operations. To document the differences in spending decisions between tobacco consuming and non-consuming households, a student $t$ test was run and tested using regression analysis on whether the difference can be attributed to the consumption of tobacco.

The second empirical strategy was to test corner solutions. The function $b_{n}$ is the conditional demand on tobacco of the $n^{\text {th }}$ good in the function $x_{n}=b_{n}\left(p_{n} \ldots . p_{z} ; M ; c, d\right)$. It therefore means that one gets demand for other goods on the household as a function of the price of that good, price of all goods except tobacco, which is the conditioning. To test whether having no expenditure on tobacco is as a result of abstaining from tobacco consumption or as a result of corner solutions, these conditional demand functions can be used. This is because there is possibility that some households which do not report tobacco use, especially in cross-sectional surveys, cannot be all theoretically assumed due to abstention only (John, 2008). There is possibility that the zero reporting by households is as a result of infrequent purchases, which can result to either corner solutions because of the budget constraint or sheer abstention. Corner solutions could suggest that once prices 
improve, there are consumers who will resume purchase of the product. It is therefore important to statistically test whether the zero reporting of tobacco use was due to abstentions or corner solutions. To establish this, we followed the study of Vermeulen (2003) and used a simple $t$ test where we augmented the conditional demand function with a binary variable that indicates if the household was a smoking household or a non-smoking household.

A necessary condition for non-reporting of tobacco expenditure and its correspondence to corner solution is that both non-users and users of tobacco behave according to the demand function $x_{n}=b_{n}\left(p_{n} \ldots . p_{z} ; M ; c, d\right)$. If this is the case, it means that there are households who do not set money aside for tobacco consumption because of budget constraints. We therefore test the null hypothesis for corner solution by following the test developed by Vermeulen (2003). The procedure involves testing whether the demand function depends on a binary variable $d$. Therefore, this binary variable indicates whether we observe negative expenditure on tobacco $(d=0)$ or positive expenditure on tobacco $(d=1)$. A significant conditioning binary indicator in the demand for the other commodities by all households means both non-users and users of tobacco behave differently. Therefore, the null hypothesis is rejected, indicating that zero reporting by households is as a result of abstention. However, if the binary indicator $d$ is insignificant, we would not have sufficient reason for rejecting zeros to be derived from abstentions (Vermeulen, 2003; John, 2008; Chelwa \& Van Walbeek, 2014).

It is possible that both tobacco users and non-users have similar preferences on the rest of the goods in the commodity package in the household, which may result to a rejection of the null hypothesis. However, because tobacco use acts as a constraint in a tobacco users' utility function and not for a non-user, it is important that the test explores whether tobacco is weakly separable from the consumption of other commodities (Vermeulen, 2003). If there is separability of $x_{n}$ from $d$ (i.e., $\mathrm{d}$ is insignificant), it suggests that the household starts by first allocating money for tobacco. If this happens, it would generate an income effect but not a substitution effect on the rest of the household commodities.

The third empirical strategy in the paper was to test the hypothesis on whether tobacco expenditure crowds out consumption of the commodities chosen in the two sets of households. Here, Engel curves were estimated using a Quadratic Almost Ideal Demand System (QUAIDS). Estimating QUAIDS has an advantage in that it is consistent with utility theory and is consistent with Angus Deaton's Almost Ideal Demand System, and it allows one to make consideration of household income and model a commodity as a necessity or luxury (Banks et al., 1997). Since this is a non-parametric analysis of consumer expenditure pattern, Engel curves require quadratic terms in the 
logarithm of expenditure, something that is not possible in Almost Ideal Demand System (AIDS). This is because they have expenditure share Engel curves that are linear in the logarithm of total expenditure (Banks et al., 1997). For example, there are certain durable goods or clothing types that are regarded as necessities by higher income individuals while at the same time luxuries by lower income individuals.

The paper assumes that a household seeks to maximize a collective utility. The paper therefore estimated a system of Engel curves, each taking the following form:

$$
W_{n h}=\alpha_{1 n}+\alpha_{2 n} d_{h}+\alpha_{3 n} \ln M_{h}+\alpha_{4 n}(\ln M)_{h}{ }^{2}+\alpha_{5 n} F E+\gamma_{n} a_{j}+u_{n h} \ldots . .
$$

Equation 4 represents the conditional Engel curves of the conditional demand functions discussed in the theoretical framework presented in section 3.3. In the equation estimated, $W_{i h}$ is expenditure portion of commodity $n$ in household $h$ after deducting the expenditure portion of tobacco in the household. $d_{h}$ is a binary dummy variable, which is represented by a value of one (1) if household $h$ reports a positive expenditure of tobacco in a month and zero (0) if there is no expenditure of tobacco in the household. $\ln M_{h}$ is the natural logarithm of total monthly expenditure, excluding expenditure on tobacco. $(\ln M)_{h}{ }^{2}$ is the square of $\ln M_{h}$ in household $h \cdot a_{i h}$ is a vector of household characteristics that include natural logarithms of characteristics such as age of head of household, household size, average age of the adults in the household, years of schooling of the household head, sex of household head, principal source of household income, and occupation of household head. Other characteristics include the proportion of adults in the household (household structure) and the number of employed persons in the household. For the purpose of this paper, adults are defined as those above 18 years. The controls used in $\boldsymbol{a}$ are standard ones used in literature for crowding out effects of tobacco (Chelwa \& Van Walbeek, 2014; John, 2008; Pu et al., 2008, John,

Ross \& Blecher, 2012; San \& Chaloupka, 2016). $\boldsymbol{u}_{n h}$ is the error term and is assumed to be normally distributed and has a mean value of zero. Crowding out was then established if the coefficient of $d$, i.e., $\alpha_{2 n}$ in equation (4), was negative and statistically significant.

There is a possibility that $d, \ln M_{h}$, and $(\ln M)_{h}{ }^{2}$ are endogenous, i.e., correlated to the error term $u_{n h}$. In addressing this, this paper followed the study of John (2008), Pu et al. (2008), Chelwa and Van Walbeek (2014), and San and Chaloupka (2016) by instrumenting for tobacco expenditure $d$. The use of an instrumental variable not only makes the estimates consistent but also ensured they are unbiased. The essay adopts Chelwa and Walbeek (2014) assumption that $\operatorname{cov}(\mathrm{x}, \varepsilon) \neq 0$. It further states that the choice of the 
instrumental variable is very important because the instrumental variable chosen has to be one that influences $W_{n h}$ only through its influence on tobacco.

In addition to this, it has to influence $W_{n h}$ only through its impact on $\ln M_{h}$. Given this scenario, the candidates for the instrumental variable were adult male and adult female ratio for tobacco and total household expenditure (which is used as a proxy income) for $\ln M_{h}$. As John (2008), Pu et al. (2008), and Chelwa and Van Welbeek (2014) opinioned, we instrumented for $d$ with adult sex ratio. The rationale behind this choice of instrument is that male adult smoking prevalence is higher in Kenya than adult females, and they are therefore more likely to use tobacco. The study also makes an assumption that the instrumental variable of adult sex ratio is not correlated with the error term $u_{n h}$. To strengthen the case for the choice of the instrumental variable, we assessed the results of the coefficient of the F statistics reported at the firststage probit for the regression of the instrumental variables, Thus, they were then evaluated to see if they were strong, i.e., if $\mathrm{F}$ statistic was equal or greater than 10 (Stock et al., 2002). This confirmed the validity of the choice.

It is also possible that another variable which was not specified in equation 2 might simultaneously influence a household's expenditure on tobacco and other commodities in the household. It is important we account for this endogeneity to ensure that the coefficients specified in the demand system are both consistent and unbiased. The OLS procedure specified previously assumed that $d$ is exogenous, i.e., not related to the error term. Additionally, $\ln M_{h}$ and $(\ln M)_{h}{ }^{2}$ are also likely to be endogenous in a similar manner. We therefore account for this possible endogeneity. In doing so, we first estimated the first stage regressions involving the endogenous variables and potential instruments (Baltagi, 2008). The potential instruments assessed included total expenditure, household size, years of schooling of household head, household structure, age of household head, average household age, and average child age. Afterwards, at the second stage, the predicted values from the first stage regression are substituted for the endogenous variables in equation 4.

As a result of the dichotomous nature of $d$, the first stage regression between $d$ and adult sex ratio (instrument) will likely be non-linear. Therefore, we best estimated it using a probit. This ensures that the predicted values for $d, \hat{d}$ are bounded between 0 and 1 , something that is not certain when one uses a linear estimation. However, using this estimation introduces the complication of forbidden regression, which is a situation where predicted values from the first stage are directly applied to a second stage, which is linear (Wooldridge, 2002). The challenge with this is that one risks non-zero 
correlation between $\hat{d}$ and the first stage residuals (Angrist \& Pische, 2009). To prevent this from happening, we followed the suggestions made by Heckman (1978), Wooldridge (2002), and Angrist and Pische (2009). In addition, we also used the predicted values from the first stage probit $(\hat{d})$ as an instrument for $d$.

To implement the instrumenting technique above, this essay adopts Chelwa and Van Walbeek (2014) approach where equation 4 is estimated using 3SLS combined with a Seemingly Unrelated Regression (SURE). This would in effect make it a four stage least squares procedure because the first two stages involve estimating a probit function for $d$ and using the estimated

function to generate the predicted values, $\hat{d}$, which are used as instruments for $d$ in the third stage. The SURE method assumes the fourth stage because it corrects errors associated with regression coefficients within household correlation with error term (Zeller, 1962).

\section{Data}

The data for this paper comes from the 2005/2006 Kenya Integrated Household and Budget Survey (KIHBS) conducted by the Kenya National Bureau of Statistics. This survey was nationally representative and used a twostage stratified cluster sampling whereby 1,343 clusters comprising of 482 urban clusters and 861 rural clusters where selected in the first stage. In the second stage, a total of 13, 430 households from the 1,343 clusters and divided into 8,610 rural households and 4,820 urban households were selected.

The KIHBS survey collects a rich set of data based on the living conditions of Kenyan households in the area of education, health characteristics, child nutrition, household income levels and transfers, employment status, income sources, food production and consumption, household expenditure patterns, access to clean water, household access to social amenities, access to credits and shocks, and many more. The expenditure section in the survey (section IJKL) asks each household to report the total expenditure of a commodity over time, ranging from per week to one month. Where the survey reports consumption over a period of seven days, this paper assumes a uniform consumption amount per week and multiplies the same by a four to estimate the monthly consumption of all the expenditures. In some cases, such as schooling, the households give an annual expenditure. In such cases, this annual expenditure is divided by twelve to give the monthly expenditure. In this paper, the expenditure, as stated earlier, focuses on the following commodities: Alcohol, tobacco, food, healthcare, entertainment, transport and communication, house care, personal care, electricity and lighting, rent, clothing, and alternative energy. 


\section{Results and Discussion Description of Results}

Table 1 shows some of the summary statistics from the 2005/2006 KIHBS. The full sample consisted of 13,212 households with 1,775 households reporting positive tobacco use (13.43\%). The KIHBS survey suggests that the average household size of Kenyan households is 5.05, with adults generally comprising $49.60 \%$ of Kenyan households. For the purposes of this paper, adults are defined as those who are 18 years or older in a household. The adults have a general average age of 37.25 years and the average age of the head of the household in the survey is 44.52 years. Children in this paper are defined as those under the age of 18 years and the survey results indicate that the average age of children in the households is 3.68 years. The average years of schooling for the household head in the households surveyed was 18 years. Based on the percentage of adults in the households, the results suggest that the number of adults in the households is at an average of 2.52 and the average number of people employed in Kenyan households from the full sample is 1.61 .

Table 1. Summary Statistics- Full Sample

\begin{tabular}{|c|c|c|c|c|}
\hline $\begin{array}{l}\text { Line } \\
\text { No. }\end{array}$ & Statistic & Full Sample & Urban & Rural \\
\hline 1 & Number of households & 13,212 & 4,725 & 8,487 \\
\hline 2 & $\begin{array}{l}\text { Percentage of households in urban } \\
\text { areas }\end{array}$ & $35.76 \%$ & $100 \%$ & N/A \\
\hline 3 & $\begin{array}{l}\text { Percentage of households in rural } \\
\text { areas }\end{array}$ & $64.24 \%$ & N/A & $100 \%$ \\
\hline 4 & Average monthly tobacco expenditure & 373.33 & 679.80 & 291.27 \\
\hline 5 & $\begin{array}{l}\text { Percentage of households reporting } \\
\text { positive tobacco expenditure }\end{array}$ & $13 \%$ & $11 \%$ & $15 \%$ \\
\hline 6 & $\begin{array}{l}\text { Tobacco share among tobacco } \\
\text { spending households }\end{array}$ & $6.32 \%$ & $6.70 \%$ & $6.22 \%$ \\
\hline 7 & Monthly household expenditure & $8,342.25$ & $14,937.22$ & $6,091.94$ \\
\hline 8 & Average household size & 5.05 & 4.13 & 5.56 \\
\hline 9 & Percentage of adults in the household & $49.90 \%$ & $56.90 \%$ & $47.12 \%$ \\
\hline 10 & Average age of household head & 44.52 & 39.16 & 47.50 \\
\hline 11 & $\begin{array}{l}\text { Average age of adults in the } \\
\text { household }\end{array}$ & 37.25 & 35.24 & 38.37 \\
\hline 12 & $\begin{array}{l}\text { Average age of children in the } \\
\text { household }\end{array}$ & 3.69 & 2.58 & 4.30 \\
\hline 13 & $\begin{array}{l}\text { Average years of schooling of } \\
\text { household head }\end{array}$ & 10.16 & 11.46 & 9.21 \\
\hline 14 & $\begin{array}{l}\text { Average number of employed people } \\
\text { in the household }\end{array}$ & 1.61 & 1.34 & 1.77 \\
\hline 15 & $\begin{array}{l}\text { Percentage of people living in high- } \\
\text { cost residences }\end{array}$ & $55.76 \%$ & $49.04 \%$ & $59.45 \%$ \\
\hline
\end{tabular}




\begin{tabular}{|r|l|l|l|l|}
\hline $\begin{array}{c}\text { Line } \\
\text { No. }\end{array}$ & Statistic & Full Sample & Urban & Rural \\
\hline 16 & $\begin{array}{l}\text { Percentage of people living in } \\
\text { medium-cost residences }\end{array}$ & $15.34 \%$ & $33.53 \%$ & $5.32 \%$ \\
\hline 17 & $\begin{array}{l}\text { Percentage of people living in low- } \\
\text { cost residences }\end{array}$ & $28.89 \%$ & $17.33 \%$ & $35.24 \%$ \\
\hline 18 & Food & $54.07 \%$ & $45.36 \%$ & $56.41 \%$ \\
\hline 19 & Alcohol & $4.37 \%$ & $5.04 \%$ & $4.19 \%$ \\
\hline 20 & Health care & $2.83 \%$ & $1.94 \%$ & $3.07 \%$ \\
\hline 21 & School & $0.05 \%$ & $0.05 \%$ & $0.05 \%$ \\
\hline 22 & Clothing & $6.16 \%$ & $4.50 \%$ & $6.60 \%$ \\
\hline 23 & Water & $1.28 \%$ & $1.58 \%$ & $1.20 \%$ \\
\hline 24 & Housing & $2.11 \%$ & $8.22 \%$ & $0.55 \%$ \\
\hline 25 & Electricity & $3.14 \%$ & $2.11 \%$ & $3.42 \%$ \\
\hline 26 & Alternative Energy & $6.49 \%$ & $7.32 \%$ & $6.26 \%$ \\
\hline 27 & Transport and Communication & $5.50 \%$ & $9.97 \%$ & $4.30 \%$ \\
\hline 28 & Entertainment & $0.79 \%$ & $1.17 \%$ & $0.69 \%$ \\
\hline 29 & House Care & $2.73 \%$ & $2.13 \%$ & $2.89 \%$ \\
\hline 30 & Personal Care & $4.20 \%$ & $4.31 \%$ & $4.17 \%$ \\
\hline
\end{tabular}

Source: Author's Computation using Kenya Integrated Household and Budget Survey 2005/2006

\section{Differences in Expenditure Shares}

Table 2 shows the difference in expenditures between smoking and non-smoking households for the full, rural and urban samples. The presentation of results for both rural and urban areas was carried out because the survey collects a rich set of data on living conditions, which was split into rural and urban households. Further analysis in this paper for both rural and urban areas was done by assessing expenditure patterns of the top 50\% and bottom $50 \%$ of each categorization. In this paper, the top 50\% is referred to as 'richer' households and the bottom 50\% to as the 'poorer' households.

These differences are expressed in percentage points. Positive implies that smoking households allocate a greater share of their expenditure to that category item compared to non-smoking households. When it is negative, it implies that smoking households spend a lower proportion of their budgets on the category item than the smoking households. The results suggest that smoking households allocate less monies to food, healthcare, clothing, housing, electricity, alternative energy, transport and communication, entertainment, house care and personal care. The difference in health care, school, housing, electricity, alternative energy, transport and communication, entertainment, house care and personal care are statistically significant. 
Generally, smoking households allocate more funds towards the consumption of alcohol and water than non-smoking households. Thus, allocation to alcohol is statistically significant.

In summary, Table 2 shows that there are differences in the way smoking and non-smoking households allocate their monthly expenditure, with the difference being statistically different in many cases. It is therefore important to investigate whether these differences and patterns observed are in any way related to the smoking status of the households.

Table 2. Difference in Mean Expenditures Shares between Smoking and Non-Smoking Households

\begin{tabular}{|l|r|r|r|}
\hline Expenditure Share on & \multicolumn{1}{c|}{$\begin{array}{c}\text { Full } \\
\text { Sample }\end{array}$} & \multicolumn{1}{c|}{$\begin{array}{c}\text { Urban } \\
\text { Sample }\end{array}$} & \multicolumn{1}{c|}{$\begin{array}{c}\text { Rural } \\
\text { Sample }\end{array}$} \\
\hline Food & $-6.3 \%$ & $0.07 \%$ & $-1.61 \% * *$ \\
\hline Alcohol & $1.52 \% * *$ & $4.39 \% *$ & $0.83 \%$ \\
\hline Health care & $-0.53 \% * *$ & $-0.68 \% * *$ & $-0.55 \% *$ \\
\hline School & $-5.96 \% *$ & $-8.86 \% * * *$ & $-4.74 \%$ \\
\hline Clothing & $-0.52 \% *$ & $-1.07 \% *$ & $-0.47 \%$ \\
\hline Water & $0.03 \%$ & $-0.37 \% * *$ & $0.2 \%$ \\
\hline Housing & $-1.45 \% * * *$ & $-3.80 \% * * *$ & $-0.09 \%$ \\
\hline Electricity & $-0.71 \% * * *$ & $-0.65 * * *$ & $-0.81 \% * * *$ \\
\hline Alternative Energy & $-2.04 \% * * *$ & $-1.52 \% * * *$ & $-2.15 \% * * *$ \\
\hline Transport and Communication & $-1.85 \% * * *$ & $-0.18 \%$ & $-2.34 \% * * *$ \\
\hline Entertainment & $-0.37 \% *$ & $-0.43 \% *$ & $-0.34 \%$ \\
\hline House Care & $-0.44 \% * * *$ & $-0.24 \% *$ & $-0.55 \% * * *$ \\
\hline Personal Care & $-1.20 \% * * *$ & $-1.29 * * *$ & $-1.16 \% * * *$ \\
\hline
\end{tabular}

Significance levels [*** $\mathrm{p}<0.01, * * \mathrm{p}<0.05, *<0.1]$

Source: Author's Analysis using KIHBS 2005/2006

Table 3 shows the expenditure shares of tobacco across expenditure quintiles for smoking households only. The paper first constructed expenditure quintiles on total expenditure across both urban and rural households to determine the expenditure spend across smoking households. The results suggest that urban tobacco smoking households have a higher expenditure allocation for tobacco use across all quintiles compared to rural households, with those at the lower quintiles for both urban and rural households having a higher allocation. For instance, the $1^{\text {st }}$ quintile for urban households allocates $11.83 \%$ compared to $4.71 \%$ for the $5^{\text {th }}$ quintile. In the case of rural households, the $1^{\text {st }}$ quintile allocates $10.04 \%$ compared to $4.67 \%$ for the $5^{\text {th }}$ quintile. This could suggest that poorer households, which have the lowest expenditures, spend more in tobacco expenditure compared to fairly well of households.

Table 3. Tobacco Expenditure Shares across Expenditure Quintiles for Smoking Households

\begin{tabular}{|c|c|c|c|c|c|c|}
\hline Quintile & 1 & 2 & 3 & 4 & 5 & Total \\
\hline Urban & $11.83 \%$ & $7.71 \%$ & $5.48 \%$ & $4.78 \%$ & $4.71 \%$ & $6.70 \%$ \\
\hline Rural & $10.04 \%$ & $6.56 \%$ & $5.3 \%$ & $5.25 \%$ & $4.67 \%$ & $6.22 \%$ \\
\hline
\end{tabular}

Source: Author's Analysis using KIHBS 2005/2006 


\section{Ordinary Least Squares}

This section investigates whether there is a causal interpretation to the differences discussed in the previous section. This basically means that this section seeks to find out if the expenditure share differences between the smoking and non-smoking households are as a result of the smoking households allocating more expenditure towards tobacco.

The difference in expenditure patterns observed in Tables 2 could be as a result of confounding variables, i.e., characteristics other than the tobacco smoking status of the household. For example, the household structure or the household's socio-economic status may be the cause of the difference in the expenditure patterns. To control these confounders, we can use ordinary least squares (OLS) where we regress expenditure shares on the household smoking status and a number of control variables that would represent the household structure and household socio-economic status. This would therefore mean that we estimate equation 3 by OLS and report the results of this in Table 4. However, we present only the results of the coefficient on d (smoking status) with the full results of the OLS estimation presented in an appendix later.

In Table 4, a negative coefficient on $\mathrm{d}$ suggests that smoking households allocate less expenditure in that category of expenditure item in the household when compared to non-smoking households when other variables are controlled. This table, to a great extent, replicates Table 2 from a qualitative perspective. The results suggest that for the full sample, crowding out occurs for housing, alternative energy, transport and communication, and personal care with all the instances being statistically significant at $1 \%$. It also occurs for home care with a statistical significance of 5\%. For the urban sample, crowding out occurs for alternative energy, transport and communication, personal care (all with statistical significance of 1\%) and for house care at $5 \%$ statistical significance. In the rural sample, it occurs for housing and alternative energy (1\% statistical significance), clothing (5\% statistical significance), and personal care (10\% statistical significance). Finally, we observe that commodities of the top $50 \%$ of the sample experience most crowding out compared to those of the bottom $50 \%$. 
Table 4. Ordinary Least Squares (OLS) Estimates for the Coefficient on $\mathrm{d}$

\begin{tabular}{|c|c|c|c|c|c|}
\hline Coefficient on $d$ in: & Full Sample & Urban H/holds & Rural H/holds & Top 50\% & Bottom 50\% \\
\hline \multirow{2}{*}{ Food } & \multirow{2}{*}{$0.011(0.007)$} & $0.0112(0.009)$ & \multirow{2}{*}{$0.006(0.011)$} & $0.044(0.014) * * *$ & $0.006(0.009)$ \\
\hline & & 0.033 & & $0.029(0.004)^{* * *}$ & $0.042(0.003)^{* * *}$ \\
\hline Alcohol & $0.037(0.002)^{* * *}$ & $(0.003)^{* * *}$ & $0.045(0.004)^{* * *}$ & & \\
\hline Health care & $-0.003(0.003)$ & $-0.003(0.004)$ & $-0.002(0.004)$ & $-0.005(0.004)$ & $0.002(0.004)$ \\
\hline School & $-0.001(0.001)$ & $-0.001(0.001)$ & $-0.001(0.003)$ & $-0.0003(0.001)$ & $0.175(0.355)$ \\
\hline Clothing & $-0.001(0.004)$ & $-0.007(0.005)$ & $-0.019(0.007)^{* *}$ & $0.002(0.007)$ & $-0.003(0.006)$ \\
\hline Water & $0.101(0.088)$ & $0.002(0.001)$ & $-0.001(0.002)$ & $0.001(0.002)$ & $-0.0003(0.001)$ \\
\hline & & & - & - & $-0.007(0.004)^{*}$ \\
\hline Housing & $-0.007(0.003)^{* * *}$ & $-0.0005(0.001)$ & $0.019(0.007)^{* * *}$ & $0.013(0.005) * * *$ & \\
\hline Electricity & $-0.002(0.001)$ & $-0.001(0.002)$ & $-0.003(0.002)$ & $-0.005(0.003)^{*}$ & $-0.002(0.002)$ \\
\hline & & - & - & - & $-0.014(0.004) * * *$ \\
\hline Alternative Energy & $-0.014(0.003) * * *$ & $0.012(0.004) * * *$ & $0.015(0.005)^{* * *}$ & $0.015(0.005) * * *$ & \\
\hline Transport and & & & & - & $-0.008(0.005)$ \\
\hline Communication & $-0.010(0.004)^{* * *}$ & $-0.01(0.004)^{* * *}$ & $-0.007(0.007)$ & $0.016(0.006)^{* * *}$ & \\
\hline Entertainment & $-0.001(0.001)$ & $-0.002(0.002)$ & $-0.0005(0.002)$ & $-0.003(0.002)^{*}$ & $-0.001(0.002)$ \\
\hline House Care & $-0.002(0.001)^{* *}$ & $-0.003(0.001)^{* *}$ & $-0.0004(0.002)$ & $-0.005(0.002)^{*}$ & $-0.001(0.001)$ \\
\hline & & - & & 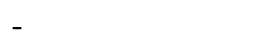 & $-0.006(0.002)^{* * *}$ \\
\hline Personal Care & $-0.007(0.002) * * *$ & $0.008(0.002)^{* * *}$ & $-0.006(0.003)^{*}$ & $0.015(0.004)^{* * *}$ & \\
\hline Observations & 9,281 & 5,388 & 3,870 & 3,887 & 5,371 \\
\hline
\end{tabular}

Significance levels [*** $\mathrm{p}<0.01, * * \mathrm{p}<0.05, *<0.1]$

Source: Author's Analysis using Kenya Integrated Household and Budget Survey 2005/2006 


\section{Three-Stage Least Squares (3SLS)}

The results presented in Table 4 assume that $d$ is exogenous, i.e., not correlated to the error term. However, it is likely that $d$ in equation 4 is endogenous, for instance in a situation where a household decides to spend on tobacco only after making other household expenses or where we have a variable not specified in the equation but contained in the error term. Thus, this influences a household's decision on tobacco spending simultaneously with the spending on other commodities. In addition to this, previous studies have suggested that and are likely to be endogenous in the same way (Vermeulen, 2003; John, 2008; Pu et al., 2008).

To account for possible endogeneity of $\mathrm{d}$, , and to prevent biased and inconsistent coefficient estimates in the demand system, this paper estimated equation 3-2 using 3SLS. The first two stages involved estimating a probit function for $\mathrm{d}$ and using the estimated function to generate the predicted values, , which are used as instruments for $\mathrm{d}$ in the third stage. These results are presented in Table 5 below.

The results suggest that food is given a smaller expenditure allocation in the full sample and rural households. This is with the results from the full sample suggesting that the results are statistically significant at $1 \%$ level, and the results from rural households being at 5\% significance level. Urban smoking households allocate less expenditure in health care compared to nonsmoking households, with the difference being only statistically significant at $10 \%$ with the bottom $50 \%$ of the survey being the ones mainly impacted. Rural smoking households allocate more resources in electricity and alternative energy than non-smoking households. This is with results being statistically significance at $5 \%$ for electricity and $10 \%$ for alternative energy. In the full sample, smoking households allocate more in terms of electricity and alternative energy compared to non-smoking households, with results being statistically significant at 5\% for electricity and $1 \%$ for alternative energy. Also, smoking households in rural areas allocate less in house care, with results being statistically significant at $10 \%$. The results, however, suggest that it is the top 50\% of the sample that experience this crowding out of house care compared to the bottom 50\%. In the full sample, the smoking households allocate less in house care, with results being statistically significant at $1 \%$. 
Table 5. Three Stage Least Squares (3SLS) Estimates for the Coefficient on d

\begin{tabular}{|llllll|}
\hline Coefficient on $\boldsymbol{d}$ in: & Full Sample & Urban H/holds & Rural H/holds & Top 50\% & Bottom 50\% \\
\hline Food & $-1.019(0.556) * *$ & $1.423(1.261)$ & $-1.870(0.885) * *$ & $-2.143(2.36)$ & $-1.297(1.643)$ \\
Alcohol & $-0.05(0.149)$ & $-1.375(0.322)^{* * *}$ & $0.210(0.240)$ & $0.408(0.614)$ & $-1.717(0.451) * * *$ \\
Health care & $-0.180(0.231)$ & $-0.869(0.509)^{*}$ & $0.046(0.367)$ & $-0.681(0.728)$ & $-1.294(0.795) *$ \\
School & $-0.064(0.092)$ & $-0.058(0.310)$ & $-0.051(0.118)$ & $-0.009(0.114)$ & $0.175(0.355)$ \\
Clothing & $-0.327(0.341)$ & $-0.359(0.720)$ & $-1.953(0.547)$ & $-0.262(1.318)$ & $0.053(1.078)$ \\
Water & $0.101(0.088)$ & $-0.221(0.226)$ & $0.069(0.133)$ & $-0.441(0.399)$ & $0.121(0.248)$ \\
Housing & $0.166(0.183)$ & $0.681(0.768)$ & $-0.016(0.106)$ & $-0.410(0.449)$ & $0.465(0.659$ \\
Electricity & $0.264(0.108) * * *$ & $0.034(0.271)$ & $0.338(0.167) * *$ & $1.624(0.521)^{* * *}$ & $0.365(0.280)$ \\
Alternative Energy & $0.561(0.222) * * *$ & $0.411(0.582)$ & $0.584(0.331) *$ & $0.199(0.912)$ & $1.16(0.672) *$ \\
& & & & & \\
Transport and & & & & & $0.962(0.938)$ \\
Communication & $0.133(0.283)$ & $0.679(0.751)$ & $-0.045(0.425)$ & $0.402(0.983)$ & $-0.176(0.346)$ \\
Entertainment & $-0.006(0.102)$ & $-0.086(0.269)$ & $0.098(0.154)$ & $-0.067(0.335)$ & $0.088(0.202)$ \\
House Care & $-0.226(0.904) * * *$ & $0.012(0.177)$ & $-0.265(0.149) *$ & $-0.745(0.477)^{*}$ & $0.074)$ \\
Personal Care & $-0.053(0.148)$ & $-0.198(0.378)$ & $-0.074(0.227)$ & $-0.460(0.627)$ & $0.162(0.441)$ \\
\hline Observations & 5,542 & 1,688 & 3,854 & 2,298 & 3,244 \\
\hline
\end{tabular}
Significance level $[* * * \mathrm{p}<0.01, * * \mathrm{p}<0.05, *<0.1]$

Source: Author's Analysis using Kenya Integrated Household and Budget Survey 2005/2006 


\section{Discussion of Findings}

This paper adds to the literature on how tobacco expenditure crowds out consumption of items in households in two ways. First, the paper uses data from a low-income country, Kenya, where a lot of households are poor. Secondly, this paper also uses the method of instrumental variables as is the standard method in literature but goes further and uses less stringent assumptions on the instruments.

The econometric analysis carried out suggests that tobacco crowds out the consumption of food, alcohol health care, schooling, clothing, entertainment, house care, and personal care. In the general sample, the crowding out is statistically significant on food and house care. The study also suggests that the magnitude and pattern of crowding out of tobacco on other household expenditure items is subject to geographical location and socioeconomic standing of households. Further econometric analysis shows that crowding out of tobacco expenditure on health care is more among the poor. This is because at the bottom $50 \%$ of the surveyed households, the crowding out is statistically significant. The crowding out of tobacco on house care seems to be also more among the high income households and among the rural households as the results suggest that this is statistically significant as can be seen in Table 3.

This study shows that tobacco crowds in consumption of goods such as water, electricity, alternative energy, transport and communication and housing for the general housing, albeit with a mixed pattern where crowding in is subject to the geographical location and socio-economic standing. For instance, tobacco crowds in consumption of water and housing for those who are poor but seems to crowd out consumption of water and housing among the richer households. However, tobacco crowds in consumption of all households for electricity, alternative energy, and transport and communication. Crowding in of tobacco expenditure on other household items has been found in Wang et al. (2006) and Koch and Tshiswaka Kashalala (2008), who both stated that tobacco crowds in expenditure on alcohol. John (2008) highlighted that tobacco consumption has a positive relation with the consumption of health care, clothing, and fuels.

\section{Conclusions and Policy Implications}

The results suggest that tobacco crowds out the consumption of food, health care, schooling, clothing, entertainment, house care, and personal care. In the general sample, the crowding out is statistically significant on food and house care. The paper also suggests that the magnitude and pattern of crowding out of tobacco on other household expenditure items is subject to geographical location and socio-economic standing of households. The study concludes that tobacco crowds in consumption of goods such as water, 
electricity, alternative energy, transport and communication and housing for the general housing, albeit with a mixed pattern where crowding in is subject to the geographical location and socio-economic standing. For instance, tobacco crowds in consumption of water and housing for those who are poor but seems to crowd out consumption of water and housing among the richer households. However, tobacco crowds in consumption of all households for electricity, alternative energy, and transport and communication. To have a conclusive suggestion on whether tobacco crowds out consumption of household goods and services, the paper, however, recommends that tobacco control should be an integral part of governments' poverty alleviation strategy. This is because the results show that poorer households in Kenya will benefit from reduction in tobacco consumption, since they would have higher disposable income that could be spent in the purchase of food, education, and clothing.

\section{References:}

1. Angrist, J.D. \& Pischke, J. (2009). Mostly Harmless Econometrics: An Empiricist's Companion. Princeton University Press.

2. Baltagi, B. H. (2008), Econometrics ( $4^{\text {th }}$ edition). Springer.

3. Banks, J., Blundell, R. \& Lewbel, A. (1997). "Quadratic Engel curves and consumer demand". The Review of Economics and Statistics, 79(40): 527- 539 .

4. Becker, G.S. (1974). "A theory of marriage". In Schultz, T.W (Ed), Economics of the Family. Chicago: University of Chicago Press.

5. Chelwa, G. \& Van walbeek, C. (2014). Assessing the causal impact on tobacco expenditure on household spending patterns in Zambia. Working Paper 453. South Africa: ERSA.

6. Efroymson, D., Ahmed, S. \& Townsend, J. (2001). "Hungry for tobacco: An analysis of the economic impact of tobacco consumption on the poor in Bangladesh". Tobacco Control, 10(1): 212-217.

7. Eriksen, M., MacKay, J. \& Ross, H. (2015). The tobacco atlas. Atlanta, GA: American Cancer Society.

8. Forouzanfar, M.H., Alexander, L. \& Anderson, H.R. (2015). "Global, regional, and national comparative risk assessment of 79 behavioural, environmental and occupational, and metabolic risks or clusters of risks in 188 countries, 1990-2013: A systematic analysis for the global burden of disease study". Lancet, 386: 2287-2323. http://dx.doi.org/10.1016/s0140-6736(15)00128-2

9. Heckman, J.J. (1978). "Dummy endogenous variables in a simultaneous equation system". Econometrica, 46(6): 931 - 959. 
10. John, R.M. (2008). "Crowding out effect of tobacco expenditure and its implications on household resource allocation in India". Social Science and Medicine, 21(15): 1356-1367.

11. John, R.M., Ross, H. \& Blecher, E. (2012). "Tobacco expenditure and implications for household resource allocation in Cambodia". Tobacco Control, 21(6): 341-346.

12. Kiriti, T. \& Tinsell, C. (2003). Gender inequality, poverty and human development in Kenya: Main indicators, trends and limitations. Working Paper No. 35. Social Economics, Policy and Development.

13. Koch, S.F. \& Tshiswaka-Kashalala, G. (2008). "Tobacco substitution and the poor". University of Pretoria Working Paper Series No. 2008 -32 .

14. Mathers, C.D. \& Loncar, D. (2006). Projections of global mortality and burden of disease from 2002 to 2030. PLoS Med, 3(11): 442.

15. Pu, C.L., Chou, V. \& Lan, C. (2008). "The crowding-out effects of tobacco and alcohol where expenditure shares are low: Analyzing expenditure data for Taiwan". Social Science and Medicine, 9(1): 1979-1989.

16. Republic of Kenya (2007a). Tobacco Control Act. National Council for Law Reporting. Nairobi: Government Printer.

17. Republic of Kenya (2007b). Statistical Abstract, Kenya National Bureau of Statistics. Nairobi: Government Printer.

18. Republic of Kenya (2009). Statistical Abstract, Kenya National Bureau of Statistics. Nairobi: Government Printer.

19. Republic of Kenya (2014). Kenya Demographic and Health Survey (KDHS). Available from: http://dhsprogram.com/pubs/pdf/FR308/FR308.pdf

20. Republic of Kenya (2015). Statistical Abstract, Kenya National Bureau of Statistics. Nairobi: Government Printer.

21. Samuelson, P.A. (1956). "Social indifference curves". Quarterly Journal of Economics, 70(1): 1-22.

22. San, S. \& Chaloupka, F. (2016). "Impact of tobacco expenditures on spending within Turkish households". Tobacco Control, 2(1),1-6.

23. Stock, J.H, Wright, J.H. \& Yogo, M. (2002). "A survey of weak instruments and weak identification in Generalized Method of Moments". Journal of Business and Economics Statistics, 20(4): 518529.

24. Vermeulen, F. (2003). "Do smokers behave differently? A tale of zero expenditures and separability concepts". Economics Bulletin, 4(6): 1 -7 . 
25. Wood, D.M., Mould, M.G., Ong, S.B. \& Baker, E.H. (2005). "Pack year" smoking histories: what about patients who use loose tobacco"? Tobacco Control,14: 141-142.

26. Wooldridge, J.M. (2002). Econometric Analysis of Cross Section and Panel Data. MIT Press

27. Zellner, A. (1962). "An efficient method for estimating Seemingly Unrelated Regressions and tests for Aggregation Bias". Journal of the American Statistical Association, 57(298): 348-368. 